\title{
Evaluation of the hospital environment for women with endometrial cancer
}

\author{
Joanna Skręt-Magierło, ${ }^{1,2}$ Renata Raś2, Edyta Barnaś', Andrzej Skręt ${ }^{2}$ \\ ${ }^{1}$ Institute of Obstetrics and Emergency Medicine, University of Rzeszow, Poland \\ ${ }^{2}$ Clinical Department of Obstetrics and Gynecology, Rzeszow State Hospital, Rzeszow, Poland
}

Skręt-Magierło J, Raś R, Barnaś E, Skręt A. Evaluation of the hospital environment for women with endometrial cancer. Ann Agric Environ Med. 2016; 23(3): 511-516. doi: 10.5604/12321966.1219201

\begin{abstract}
Introduction and objectives. The aim of the study was describe the factors determining the evaluation of the hospital environment, especially satisfaction with care and individual needs of cancer patients.

Material and methods. The study comprised 80 women with endometrial cancer diagnosed and treated surgery in the Clinic of Gynaecology and Obstetrics in Rzeszow, Poland, between 2011-2012. The study used 3 questionnaires: the Goals Attainment Scaling (GAS) questionnaires, and questionnaires developed by the EORTC Quality of Life group, i.e. the QLQ C-30 (general module) and the In- PATSAT-32.

Results. Respondents indicated 36 goals/expectations and the most common (over 50\%) concerned the normal course of the post-operative period. The overall index of all goals which were met was 7.0 points. General quality of life reported by respondents before surgery was at a medium level $(52.3 \pm 16.8 \%)$. Emotional functioning received the lowest scores (61.0 $\pm 18.8 \%)$. Most respondents assessed manual skills of hospital doctors and nurses as the best in the In-PATSAT 32 scale i.e. $69.9 \pm 14.7 \%$ and $67.3 \pm 16.1 \%$, respectively. The worst ratings concerned access to hospital from the outside (50.8 $\pm 16.9 \%)$ and easy orientation inside the buildings (55.9 $\pm 16.0 \%)$.

Conclusions. Analysis of correlations between GAS and the In-PATSAT32 scales proved that they cannot be used interchangeably since they measure different aspects of a patient's satisfaction with hospital care. For this reason, the application of idiographic and nomothetic tests among cancer patients is helpful for evaluation of the hospital environment.
\end{abstract}

\section{Key words}

endometrial cancer, hospital environment, patient satisfaction.

\section{INTRODUCTION}

Traditionally used endpoints of oncologic therapy were remission rate, survival, and time to progression. The inclusion of QOL in oncology is increasingly common as a new end-point [1], following its developments in the field over the past 30 years [2]. There are many validated cancer specific instruments, the most widely used being: the Functional Living Index - cancer (FLIC); the European Organisation for Research and Treatment of Cancer (EORTC) QLQ C-30, and the Functional Assessment of Cancer Therapy - general (FACT-G) questionnaire [1]. Interestingly, some of them were used more often in different parts of the world: FACT-G in the USA and EORTC QLQ-C-30 in Europe and Canada.

Measures of satisfaction with care for cancer patients have been developed for clinical studies and used in hospitals. The Patient Satisfaction Questionnaire (PSQ) indirectly assesses satisfaction with services by inquiring about general healthcare attitudes, in contrast to those scales that directly assess the setting and services actually encountered, such as the Client Satisfaction Questionnaire [3]. There is also the REPERS 60 questionnaire for patients with non- metastatic cancer [4]; the Chinese Patient Satisfaction Questionnaire (ChPSQ-9) among patient with breast and lung cancer [5]; Evaluation of Patient Satisfaction among patients with breast cancer [6]; Medical Care Questionnaire (MCQ) for oncology outpatients [7]; and

Address for correspondence: Joanna Skręt-Magierło, Edyta Barnaś, Institute of Obstetrics and Emergency Medicine, University of Rzeszow, Pigonia 6, 35-310 Rzeszów, Poland

E-mail: joannaskret@wp.pl, ebarnas@interia.eu

Received: 02 September 2014; accepted: 17 October 2014 the EORTC IN-PATSAT 32 to assess patients' perceptions of the quality of hospital-based cancer care [8].

Endometrial cancer has an incidence of about 25 per 100,000 women. A comparison of overall survival with stage-related survival shows that most cases are diagnosed at an early stage, only $15 \%$ of the patients are present with advanced disease. Effective treatment of early stage disease is achieved by surgery alone. Endometrial cancer patients are usually older, and some of them are obese and suffering from other comorbidities $[9,13]$. For these reasons, clinical pathways during surgical treatment and care can be used to increase the quality of care, and increase patient satisfaction.

The European Organization for Research and Treatment of Cancer (EORTC) Quality of Life Group has developed a cross-culturally questionnaire - the EORTC IN- PATSAT 32, to assess patients' perceptions of the quality of hospital-based cancer care [8]. The measurement of patient satisfaction may constitute feedback information to clinicans in highlighting aspects of health care, and has become increasingly important for strategies to improve health care. Respect for a patient's needs and wishes is central to any human health care system [10].

Patient satisfaction can be defined as the extent to which an individual' $s$ health care experiences match his or her expectations. Satisfaction is strongly linked with the expectations of the patient [8].

The Goals Attainment Scaling (GAS) is a method which examines the individual needs of a patient and is one of the elementary components of patient-centreed care. It was first introduced in the 1960s by Kirusek and Sherman in order to assess medical outcomes in mental health settings. 
Since then, it has been modified and applied in many other fields: physical therapy, rehabilitation, early intervention, geriatrics, nursing care and communication disorders [11]. Long-term follow-up studies have related that goal achievements is related to the general quality of life measures [12]. The construct validity and criterion validity of GAS were evaluated via correlations with the following standardized outcome measures: Barthel Index, Brief Symptom Inventory, Health- Sickness Rating Scale and the Nottingham Health Profile. GAS was hypothesized to correlate strongly with standardized measures that address clinically relevant domains, which are similar to the goal areas identified in the GAS follow-up guides. GAS was also shown to correlate strongly with other measures that showed change, and it discriminated between lower and higher functional or QOL status [11]. The combination of scales of quality of life of cancer patients, and the evaluation of satisfaction with the care of the individual needs, is the main objective of the presented study..

\section{OBJECTIVES}

The aim of the study is describe the factors determining the evaluation of the hospital environment especially: 1) identify individual goals of endometrial cancer patients before hospitalization for surgery; 2) describe how patients assessed the realization of their goals; 3 ) compare the EORTC-PATSAT with GAS outcomes

\section{MATERIALS AND METHOD}

The study used three questionnaires: two nomothetic questionnaires developed by the EORTC Quality of Life group QLQ C-30 (general module) and the In-PATSAT-32; and the idiographic test-Goals Attainment Scaling (GAS). Additional questions were asked about demographics.

The QLQ C-30 is a questionnaire assessing global quality of life in cancer patients. It consists of 30 questions including three modules: functioning scales (physical functioning, role functioning, emotional functioning, cognitive functioning, and social functioning), symptom scales (fatigue, nausea and vomiting, pain, dyspnoea, insomnia, appetite loss, constipation, diarrhoea, financial difficulties), and global health status scales (global health status and quality of life). The EORTC IN-PATSAT-32 includes 32 items across 11 multiitem and three single item dimensions or 'scales'. Patients are asked to rate doctors in terms of their technical skills (3 items), interpersonal skills (3 items), information provision (3 items) and availability (2 items). Nurses are similarly rated across the same dimensions, with items phrased to represent the nursing role (total 11 items). Additional items ask patients to rate other services and the care organisation, and include items relating to interpersonal skills and information provision (3 items), waiting time (2 items) and hospital access ( 2 items). The three single items refer to the exchange of information between carers, level of comfort specific to the environment, and an overall rating of care received. All items use five-point categorical response options - 'poor' through to 'excellent'. All scores are linearly transformed to a $0-100$ scale, where a higher score indicates a higher level of satisfaction [8].
The Goals Attainment Scale (GAS) is a method of evaluating the extent to which patient's individual goals are achieved in the course of intervention. As a result, each patient has his/her own outcome measure; however, the rating system is standardised to allow statistical analysis. Traditional standardised measures include a general set of tasks (items), each rated on a defined level. In GAS, tasks are individually identified to suit the patient, and the levels are individually set around their current and expected levels of performance. An important feature of GAS is the 'a priori' establishment of the criteria representing 'successful' outcome for a particular patient, which is agreed with the patient and family before intervention starts so that everyone has a realistic expectation of what is likely to be achieved, and agrees that this would be worth striving for. Each goal is rated on a five-point scale, with the degree of attainment captured for each goal area: If a patient achieves the expected level, the score is 0 . If a better than expected outcome is achieved, scores are +1 (somewhat better) or +2 (much better). If a patient achieves a worse than expected outcome, it is rated as: -1 (somewhat worse) or -2 (much worse). Goals may be weighted to take account of the relative importance of a particular goal to an individual, and/ or the anticipated difficulty of achieving it [11].

The study group comprised 80 women with endometrial cancer hospitalised in the Clinic of Gynaecology and Obstetrics in Rzeszow, Poland. Consent was obtained from the EORTC as well as Bioethical Committee at Rzeszow University (No. 4/10/2011). Data were collected between October 2011 - February 2012.

The following patients were enrolled: women hospitalized with diagnosed endometrial cancer and qualified for surgical treatment who gave their informed written consent for surgical intervention and participation in this study. Patients were asked to fill-in the QLQ C-30 questionnaire one day before surgery, and write down five goals (expectations) related to their hospitalisation. During the postoperative period (one day before being discharged) the women filled-in the In-PATSAT-32 and assessed whether their goals were met, using a numeric scale ranging from -2 to +2 . This assessment was performed on the original form on which they wrote down their expectations the day before surgery.

Statistical analysis. Statistical analysis employed Statistica software, version 10.0. Correlations between two numerical parameters were analysed using the Spearman's rank correlation coefficient. The significance of differences concerning average levels of a numerical feature in two populations was examined with the Mann-Whitney test, which is a non-parametric alternative to the student's t-test. Correlations between two variables measured on a nominal scale were analysed using the chi-square test of independence.

\section{RESULTS}

This prospective study included 80 women with endometrial cancer in its early clinical stage according to FIGO, i.e. stages IA and IB. The mean age of respondents was 60 years. The mean BMI value was 29.4. The number of women living in a rural area was similar to the number of urban residents (50\%). Half of the group were patients with high-school education. The majority of the women also suffered from other comorbidities, mainly hypertension and diabetes. All 
women underwent surgical intervention: hysterectomy with lymphadenectomy (56.3\%) or total abdominal hysterectomy with bilateral salpingo- oophorectomy (36.3\%) (Tab. 1).

Table 1. Demographics and disease characteristics of sample groups

\begin{tabular}{lccc}
\hline Variables & Me & $\bar{x} \pm s$ & min-max \\
\hline Age & 60.0 & $61.7 \pm 9.5$ & $39-83$ \\
\hline BMI & 29.4 & $31.3 \pm 7.5$ & $19.5-55.1$ \\
\hline Variables & & & $\begin{array}{c}\text { Sample } \\
(\mathrm{n}=80)\end{array}$
\end{tabular}

Place of residence

\begin{tabular}{|c|c|}
\hline country & $37(46.3)$ \\
\hline town & $43(53.8)$ \\
\hline \multicolumn{2}{|l|}{ Education } \\
\hline primary & $14(17.5)$ \\
\hline vocational & $17(21.3)$ \\
\hline high school & $34(42.5)$ \\
\hline university & $15(18.8)$ \\
\hline \multicolumn{2}{|l|}{ Preoperative diagnosis } \\
\hline Uterine cancer & $76(95.0)$ \\
\hline Uterine cancer and myomas & $3(3.8)$ \\
\hline Uterine cancer and ovarian tumour & $1(1.3)$ \\
\hline \multicolumn{2}{|l|}{ Histology } \\
\hline Endometrial & $75(93.75)$ \\
\hline Mesoephroid & $1(1.4)$ \\
\hline Squamous cell & $1(1.4)$ \\
\hline serous & $2(2.8)$ \\
\hline non-epithelial & $1(1.4)$ \\
\hline \multicolumn{2}{|l|}{ FIGO staging } \\
\hline Stage 0 & $6(7.5)$ \\
\hline Stage IA & $38(47.5)$ \\
\hline Stage IB & $17(21.3)$ \\
\hline Stage II & $10(12.5)$ \\
\hline Stage IIIA & $6(7.5)$ \\
\hline Stage IIIB & $1(1.3)$ \\
\hline Stage IIIC & $1(1.3)$ \\
\hline \multicolumn{2}{|l|}{ Type of surgery } \\
\hline Hysterectomy & $29(36.3)$ \\
\hline Hysterectomy with lymphadenectomy & $45(56.3)$ \\
\hline $\begin{array}{l}\text { Total abdominal hysterectomy with single } \\
\text { salpingo-oophorectomy }\end{array}$ & $2(2.5)$ \\
\hline $\begin{array}{l}\text { Total abdominal hysterectomy with bilateral } \\
\text { salpingo-oophorectomy }\end{array}$ & $2(2.5)$ \\
\hline $\begin{array}{l}\text { Hysterectomy with bilateral salpingo- } \\
\text { oophorectomy with lymphadenectomy }\end{array}$ & $2(2.5)$ \\
\hline \multicolumn{2}{|l|}{ Coexisting diseases } \\
\hline Hypertension & $28(35.0)$ \\
\hline Diabetes & $19(23.8)$ \\
\hline Anaemia & $6(7.5)$ \\
\hline Hyperthyreosis & $3(3.8)$ \\
\hline Hepatic cirrhosis & $1(1.3)$ \\
\hline Asthma & $1(1.3)$ \\
\hline Status after heart attack & $1(1.3)$ \\
\hline Coronary disease & $1(1.3)$ \\
\hline No diseases & $36(45.0)$ \\
\hline
\end{tabular}

Analysis of the information obtained from the respondents in the preoperative period from GAS allowed the arrangement of goals according to the frequency of their indication, and mean values for their realisation were added. In general, 36 expectations were defined, the majority of which concerned the normal course of postoperative recovery. These goals were indicated by at least half of the study group. The highest scores were reported for: quick remobilisation after surgery 1.8 points (mean value), normal wound healing -1.5 points (mean value), and short period of hospitalisation after surgery - 1.4 points (mean value). The remaining goals were indicated too few times to draw any conclusions, even though they received high mean values (up to 2.0 points) (Tab. 2).

The total index of all goals achieved in the presented study group was 7.0 points, and was insignificantly higher among

Table 2. Individual expectations expressed by respondents one day before surgery

\begin{tabular}{|c|c|c|c|}
\hline All types of goals & $\mathrm{N}$ & Percentage 1 & $\bar{x}$ \\
\hline normal wound healing & 52 & $65.0 \%$ & 1.5 \\
\hline short hospitalisation after surgery & 49 & $61.3 \%$ & 1.4 \\
\hline quick remobilisation after surgery & 48 & $60.0 \%$ & 1.8 \\
\hline lack of postoperative complications & 47 & $58.8 \%$ & 1.2 \\
\hline quick removal of uterine catheter & 41 & $51.2 \%$ & 1.3 \\
\hline short period of waiting for surgery & 23 & $28.7 \%$ & 1.0 \\
\hline quick removal of a drain & 22 & $27.5 \%$ & 1.1 \\
\hline preventive analgesia after surgery & 21 & $26.3 \%$ & 1.1 \\
\hline information received before surgery & 19 & $23.8 \%$ & 0.7 \\
\hline quick urination without aid & 13 & $16.3 \%$ & 1.6 \\
\hline friendly care & 6 & $7.5 \%$ & 1.8 \\
\hline providing contact with family & 6 & $7.5 \%$ & 1.0 \\
\hline correct diagnosis & 5 & $6.3 \%$ & 2.0 \\
\hline continuous contact with doctor & 5 & $6.3 \%$ & 0.4 \\
\hline well-being & 5 & $6.3 \%$ & 1.4 \\
\hline $\begin{array}{l}\text { recommendations for home care after hospital } \\
\text { discharge }\end{array}$ & 5 & $6.3 \%$ & 0.8 \\
\hline postoperative help & 3 & $3.8 \%$ & 1.0 \\
\hline good news about future health & 3 & $3.8 \%$ & 0.7 \\
\hline well-being after analgesia & 3 & $3.8 \%$ & 1.7 \\
\hline un-aided functioning after surgery & 3 & $3.8 \%$ & 1.7 \\
\hline effective surgery & 2 & $2.5 \%$ & 2.0 \\
\hline total recovery & 2 & $2.5 \%$ & 1.0 \\
\hline prevention & 2 & $2.5 \%$ & 1.5 \\
\hline support from medical staff & 2 & $2.5 \%$ & 0.5 \\
\hline no catheter & 2 & $2.5 \%$ & 0.5 \\
\hline no drain & 2 & $2.5 \%$ & 0.5 \\
\hline no metastases & 1 & $1.3 \%$ & 0.0 \\
\hline contact with a psychologist & 1 & $1.3 \%$ & 2.0 \\
\hline trusting doctors & 1 & $1.3 \%$ & 2.0 \\
\hline specialist consultations & 1 & $1.3 \%$ & 1.0 \\
\hline help after surgery & 1 & $1.3 \%$ & 2.0 \\
\hline quick waking from anaesthesia & 1 & $1.3 \%$ & 2.0 \\
\hline maintaining catheter for longer time & 1 & $1.3 \%$ & 0.0 \\
\hline physical fitness before surgery & 1 & $1.3 \%$ & 1.0 \\
\hline weight loss & 1 & $1.3 \%$ & 2.0 \\
\hline lower scales & 1 & $1.3 \%$ & 0.0 \\
\hline no choice & 0 & $0.0 \%$ & - \\
\hline number of respondents & 80 & $100.0 \%$ & - \\
\hline
\end{tabular}

${ }^{1}$ The sums do not have to be equal to $100 \%$ since multiple answers could be selected 
Table 3. Index of achieved goals vs. selected parameters of a group

\begin{tabular}{|c|c|c|c|c|c|c|c|}
\hline elements & \multicolumn{3}{|c|}{$\mathrm{Me}$} & \multicolumn{2}{|c|}{$\bar{x} \pm s$} & \multicolumn{2}{|c|}{$\min -\max$} \\
\hline lindex of achieved goals & \multicolumn{3}{|c|}{7.0} & \multicolumn{2}{|c|}{$6.7 \pm 3.2$} & \multicolumn{2}{|c|}{$-5.0-10.0$} \\
\hline \multirow[t]{2}{*}{ analysed elements } & \multicolumn{6}{|c|}{ place of residence } & \multirow{3}{*}{$p$} \\
\hline & & ount & & & town & & \\
\hline \multirow[t]{2}{*}{ Index of achieved goals } & $\bar{x}$ & \multicolumn{2}{|c|}{$s$} & $\bar{x}$ & \multicolumn{2}{|r|}{$s$} & \\
\hline & 6.2 & \multicolumn{2}{|c|}{3.3} & 7.1 & \multicolumn{2}{|r|}{3.2} & 0.0790 \\
\hline \multirow{3}{*}{ analysed elements } & \multicolumn{6}{|c|}{ post-operative complications } & $p$ \\
\hline & \multicolumn{3}{|c|}{ no } & \multicolumn{3}{|c|}{ yes } & \\
\hline & $\bar{x}$ & Me & $s$ & $\bar{x}$ & Me & $s$ & \\
\hline Index of achieved goals & 7.0 & 7.0 & 3.0 & 1.8 & 1.0 & 3.2 & $0.0010^{* *}$ \\
\hline
\end{tabular}

Table 4. Correlation coefficients for selected factors with numerical or ordinal character vs. index of achieved goals

\begin{tabular}{ll}
\hline Independent factors & Index of achieved goals \\
\hline age & -0.07 \\
\hline discharge from hospital (day) & $-0.26^{*}$ \\
\hline waiting time for surgery & -0.08 \\
\hline education & 0.15 \\
\hline BMI & 0.12
\end{tabular}

Spearman's rank correlation coefficient where: $|R|<0.3$ - no correlation; $0.3 \leq|R|<0.5$ - weak correlation; $0.5 \leq|R|<0.7$ - moderate correlation; $0.7 \leq|R|<0.9$ - strong correlation; $0.9 \leq|R|<$ 1 - very strong correlation; $|R|=1$ - perfect correlation;

$p<0.05^{*} \quad p<0.01^{* *} \quad p<0.001^{* * *}$

town residents than among women living in the country. However, a significant difference of five points was noted between women with postoperative complications (mean value of 1.8) and without any complications (mean value of 7.0) (Table 3).

Low values of correlation were found between selected factors and the index of satisfaction. Therefore, it may be assumed that the level of satisfaction with personal goals met after medical treatment did not correlate with age, time to surgery, depression level, education, and the BMI. The only factor determining the level of satisfaction was the time of discharge from hospital $(\mathrm{p}<0.05)$. The longer the hospitalisation after surgery, the lower the index of goals met during medical treatment (Tab. 4).

The general quality of life described by respondents before surgery was on a medium level $(52.3 \pm 16.8)$. Patients received the highest scores in two domains: role functioning $(87.5 \pm 16.9)$ and physical functioning (79.1 \pm 15.7$)$. The lowest scores were noted for emotional functioning (61.0 \pm 18.8$)$. In the postoperative period, the respondents assessed the quality of received care (In-PATSAT 32). Manual skills of hospital doctors and nurses received the highest scores i.e. $69.9 \pm 14.7$ and 67.3 \pm 16.1 , respectively. Moreover, interpersonal skills of nurses were found to be very good $(64.5 \pm 15.7)$. General satisfaction with medical care was $68.4 \pm 16.8$ (Tab. 5).

The next step was to examine correlations between components of the and the index of goal realisation. Correlations were positive, which meant that the relation was logical, i.e. the higher the In-PATSAT 32 scores the higher values of the index of satisfaction with medical care, mainly care provided by nurses and hospital doctors. However, the majority of correlations were, at best, weak or moderate. This meant that the In-PATSAT32 components and the index of goals met during medical treatment measured different
Table 5. Mean values describing general quality of life (QLQ C-30) and mean scores describing satisfaction with medical care assessed with the In-PATSAT 32

\begin{tabular}{|c|c|c|c|}
\hline QLQ-C30 measures & $\mathrm{Me}$ & $\bar{x} \pm s$ & $\min -\max$ \\
\hline Global health status & $50.0 \%$ & $52.3 \% \pm 16.8 \%$ & $0.0 \%-100.0 \%$ \\
\hline Physical functioning & $80.0 \%$ & $79.1 \% \pm 15.7 \%$ & $26.7 \%-100.0 \%$ \\
\hline Role functioning & $100.0 \%$ & $87.5 \% \pm 16.9 \%$ & $50.0 \%-100.0 \%$ \\
\hline Emotional functioning & $66.7 \%$ & $61.0 \% \pm 18.8 \%$ & $0.0 \%-100.0 \%$ \\
\hline Cognitive functioning & $66.7 \%$ & $75.6 \% \pm 16.5 \%$ & $33.3 \%-100.0 \%$ \\
\hline Social functioning & $66.7 \%$ & $76.3 \% \pm 20.7 \%$ & $16.7 \%-100.0 \%$ \\
\hline Fatigue & $33.3 \%$ & $31.1 \% \pm 14.6 \%$ & $0.0 \%-66.7 \%$ \\
\hline Nausea and vomiting & $0.0 \%$ & $6.5 \% \pm 12.3 \%$ & $0.0 \%-66.7 \%$ \\
\hline Pain & $16.7 \%$ & $19.8 \% \pm 14.8 \%$ & $0.0 \%-50.0 \%$ \\
\hline Dyspnoea & $0.0 \%$ & $15.8 \% \pm 19.1 \%$ & $0.0 \%-66.7 \%$ \\
\hline Insomnia & $33.3 \%$ & $31.7 \% \pm 24.2 \%$ & $0.0 \%-100.0 \%$ \\
\hline Appetite loss & $0.0 \%$ & $16.3 \% \pm 20.5 \%$ & $0.0 \%-100.0 \%$ \\
\hline Constipation & $33.3 \%$ & $27.1 \% \pm 24.9 \%$ & $0.0 \%-100.0 \%$ \\
\hline Diarrhoea & $0.0 \%$ & $7.9 \% \pm 14.3 \%$ & $0.0 \%-33.3 \%$ \\
\hline Financial difficulties & $0.0 \%$ & $20.4 \% \pm 25.7 \%$ & $0.0 \%-100.0 \%$ \\
\hline In-PATSAT32 measures & Me & $\bar{x} \pm s$ & $\min -\max$ \\
\hline Interpersonal skills (D) & $50.0 \%$ & $59.0 \% \pm 16.8 \%$ & $25.0 \%-100.0 \%$ \\
\hline Technical skills (D) & $66.7 \%$ & $69.9 \% \pm 14.7 \%$ & $33.3 \%-100.0 \%$ \\
\hline Information provision (D) & $50.0 \%$ & $58.8 \% \pm 15.6 \%$ & $25.0 \%-100.0 \%$ \\
\hline Availability (D) & $50.0 \%$ & $59.8 \% \pm 17.3 \%$ & $25.0 \%-100.0 \%$ \\
\hline Interpersonal skills (N) & $66.7 \%$ & $64.5 \% \pm 15.7 \%$ & $25.0 \%-100.0 \%$ \\
\hline Technical skills (N) & $70.8 \%$ & $67.3 \% \pm 16.1 \%$ & $25.0 \%-100.0 \%$ \\
\hline Information provision $(\mathrm{N})$ & $50.0 \%$ & $58.3 \% \pm 17.1 \%$ & $16.7 \%-100.0 \%$ \\
\hline Availability (N) & $50.0 \%$ & $59.4 \% \pm 17.1 \%$ & $12.5 \%-100.0 \%$ \\
\hline Other hospital personnel kindnesss & $50.0 \%$ & $57.1 \% \pm 13.7 \%$ & $25.0 \%-100.0 \%$ \\
\hline Waiting time & $50.0 \%$ & $57.7 \% \pm 15.1 \%$ & $25.0 \%-100.0 \%$ \\
\hline Access & $50.0 \%$ & $50.8 \% \pm 16.9 \%$ & $25.0 \%-100.0 \%$ \\
\hline Exchange of information & $50.0 \%$ & $55.9 \% \pm 16.0 \%$ & $25.0 \%-100.0 \%$ \\
\hline Comfort/cleanliness & $50.0 \%$ & $55.6 \% \pm 17.3 \%$ & $25.0 \%-100.0 \%$ \\
\hline General satisfaction & $75.0 \%$ & $68.4 \% \pm 16.8 \%$ & $25.0 \%-100.0 \%$ \\
\hline
\end{tabular}

Table 6. Correlation between In-Patsat 32 components and patient's satisfaction with medical care

\begin{tabular}{lc}
\hline IN-PATSAT32 components & Index of achieved goals \\
\hline Interpersonal skills (D) & $0.44^{* * *}$ \\
\hline Technical skills (D) & $0.49^{* * *}$ \\
\hline Information provision (D) & $0.38^{* * *}$ \\
\hline Availability (D) & $0.47^{* * *}$ \\
\hline Interpersonal skills (N) & $0.25^{*}$ \\
\hline Technical skills (N) & $0.27^{*}$ \\
\hline Information provision (N) & $0.25^{*}$ \\
\hline Availability (N) & 0.22 \\
\hline Other hospital personel kindness & $0.38^{* * *}$ \\
\hline Waiting time & $0.36^{* *}$ \\
\hline Access & $0.24^{*}$ \\
\hline Exchange of information & $0.34^{* *}$ \\
\hline Comfort/cleanliness & 0.21 \\
\hline General satisfaction & $0.35^{* *}$ \\
\hline
\end{tabular}

Spearman's rank correlation coefficient where: $|R|<0.3$ - no correlation; $0.3 \leq|R|<0.5$ - weak correlation; $0.5 \leq|R|<0.7$ - moderate correlation; $0.7 \leq|R|<0.9$ - strong correlation; $0.9 \leq|R|<$ 1 - very strong correlation; $|R|=1$ - perfect correlation

$p<0.05^{*} \quad p<0.01^{* *} \quad p<0.001^{* * *}$ 
aspects of patients' satisfaction with hospital care, and these tools are not interchangeable. Evaluation of care provided by doctors had the greatest impact on patient's satisfaction with medical outcomes $(\mathrm{p}<0.001)$ (Tab. 6).

\section{DISCUSSION}

The age of our respondents is consistent with other reports where populations of women older than 60 years dominated [9]. Reis et al. found risk factors for endometrial cancer in Turkish women with lower education, history of hypertension or diabetes, and lower parity [13]. High values of the BMI were disturbing. The literature presents data confirming a relationship between high BMI values and the risk of cancer [14], especially endometrial cancer $[9,15]$. As far as coexisting diseases were concerned, hypertension and diabetes were the most common, which also is consistent with other reports indicating that civilisation diseases belong the group of risk factors in endometrial cancer $[16,17]$.

The presented outcomes with GAS cannot be compared with findings by other authors because there are no publications with similar research methodology in cancer patients. Recent studies present the application of GAS in gynaecological non-oncological surgery. Bovbjerg et al. published a report about women with pelvic organ prolapse who defined their goals and assessed to what extent these goals were achieved 3, 6, 12 months after surgery. With time, they scored better, indicating that they were more satisfied with their outcomes. This correlated with an improvement in quality of their lives assessed with the Pelvic Floor Diseases Questionnaire - specific measures of QOL [18]. Similar results were presented by Mahajan et al. in a group of 78 patients with urinary incontinence. Their postoperative satisfaction was stable until the third months of follow-up, but in the next nine months the authors noted reduced satisfaction, which correlated with decreased goals achievement [19]. Another study concluded that GAS proved useful for individual planning of care among patients with Pelvic Organ Prolapse (POP) [20].

In conclusion, the findings of the above-mentioned studies indicate that GAS allows the patient to beincluded in a care plan through defining personal goals concerning hospitalisation, encouraging communication and cooperation. Therefore, it is another measure helpful in the realisation of patientcentreed care.

In the current study, the general quality of life was on a medium level $(52.3 \pm 16.8)$. Similar results were obtained by Conroy et al.: on the e QLQ C-30 scale the patients' global quality of life was $58.11 \pm 22.14$; cognitive functioning $-76.04 \pm$ 24.80 and physical functioning $-78.5 \pm 18.60$. The study also validated the FACT-G, and compared with EORTC QLQ C-30 and FLIC (Functional Living Index- Cancer). FACT-G Physical Well-Being and global scores correlated with all QLQ C-30 subscales [1]. Chan et al. described a longitudinal study on the quality of life after treatment (with EORTC C-30) on 144 patients with newly-diagnosed gynaecologic cancer. The individual patient's QOL before treatment was insignificant, while the impact of treatment on the individual patient was significant in determining QOL after treatment. There was a strong correlation for all time points in most factors, indicating that the global health status, functional scales, and symptom scales exhibit a dependent change over time. Relief in symptoms was associated with improvements in functional scales [21].

In the presented study, general satisfaction with medical care was $68.4 \pm 16.8$. Hjörleifsdóttir et al. used the IN-PATSAT32 (EORTC IN-PATSAT32) version to compare satisfaction with care between 217 gender and different age groups. Overall, high satisfaction was found with communication, information and care that patients received from doctors and nurses. Patients were most satisfied with the nurses conduct, and least satisfied with the organization of service and care [22]. These results are consistent with the current results. Arrora et al. published similar findings for a group of 52 gynaecological patients receiving surgical treatment (with In-PATSAT 32). Standard of medical care provided, frequency of doctors' visits, exchange of information with doctors, friendliness of the staff, and state of the ward ranked highly $(>95 \%)$ on the patient satisfaction scales. Problems were identified with ease of access to and within the hospital, quality of food, and exchange of information with other hospital staff [23]. Another study including 80 Spanish cancer patients showed that individuals satisfied with medical care would be willing to recommend the hospital/ward to others. Correlations between the scales and single items of the QLQ-C30 and EORTC IN-PATSAT 32 were generally low, and the authors concluded that these results were in line with those of the EORTC validation study [24]. When comparing the results of the current study with those published by Jayasekara et al. among 343 newly-diagnosed adults with cancer, similar results were observed in the former: manual skills of hospital doctors and nurses, $67.8 \pm 20.1 ; 61.0 \pm 21.4$, respectively. General satisfaction was higher: 64.5 20.3 [25]. Similar results related to nursing and medical care were obtained by Balderas-Pena et al. whose study included of 476 cancer patients (breast cancer, NHL, colorectal cancer). They reported that the highest satisfaction with nursing and doctors' care was observed among patients with breast malignancies $(73.64 \pm 32.53 ; 90.0 \pm 18.25)$ and non-Hodgkin lymphomas $(63.69 \pm 37.78 ; 80.30 \pm 18.46)$ [26].

\section{CONCLUSIONS}

The presented analysis of correlations between GAS and the In-PATSAT 32 scales proved that they cannot be used interchangeably since they measure different aspects of patients' satisfaction with hospital care. For this reason, the application of idiographic and nomothetic tests among cancer patients is helpful in evaluating the hospital environment.

\section{REFERENCES}

1. Conroy T, Mercier M, Bonneterree J, Luporsi E, Lefebvre JL, Lapeyre M, Puyraveau M, Schraub S. French version of FACT-G: Validation and comparison with other cancer- specific instruments. Eur J Cancer. 2004; 40: 2243-2252.

2. Velikova G, Coens C, Efficace F, Greimel E, Groenvold M, Johson C, Singer S, van de Poll- Franse L, Young T, Bottomley A, et al. Healthrelated Quality of Life in EORTC clinical trials 30 years of progress from methodological developments to making a real impact on oncology practice. Eur J Cancer. Supl. 2012; 1: 141-149.

3. Mpinga EK, Chastonay P. Satisfaction of patients: A right to health indicator? Health Policy. 2011; 100(2-3): 144-150.

4. Defossez G, Mathoulin- Pelis S, Ingrand I, Gasquet I, Sifer- Riviere $\mathrm{L}$, Ingrand $\mathrm{P}$, et al. Satisfaction with care among patient with non- 
metastatic cancer: development and first steps validation of the REPERS 60 Questionnaire. BMC Cancer. 2007; 7: 129.

5. Wong SW, Fielding R, Wong C, Hedley A. Confirmatory Factor Analysis and Sample Invariance of the Chinese Patient Satisfaction Questionnaire (ChPSQ-9) among Patients with Breast and Lung Cancer. Value In Health. 2009; 12(4): 597-605.

6. Tastan S, Hatipoglu S, Lyigun E, Kilic S. Implemenatation of a clinical pathway in breast cancer patients undergoing breast surgery. Eur J Oncol Nurs. 2012; 16(4): 368-74.

7. Harley C, Adams J, Booth L, Selby P, Brown J, Velikova G. Patient Experiences of Continuity of Cancer Care: Development of a New Medical Care Questionnaire (MCQ) for Oncology Outpatients. Value In Health. 2009; 12(8): 1180-1186.

8. Brédart A, Coens C, Aaronson N, Chie WC, Efficace F, Conroy T, Blazeby JM, Hammerlid E, Costantini M, Joly F, Schraub S, Sezer O, Arraras JI, Rodary C, Costantini A, Mehlitz M, Razavi D, Bottomley A. EORTC Quality of Life Group and EORTC Quality of Life Unit. Determinants of patient satisfaction in oncology settings from European and Asian countries: preliminary results based on the EORTC IN-PATSAT32 questionnaire. Eur J Cancer. 2007; 43(2): 323-330.

9. Van den Bosch T, Coosemans A, Morina M, Timmerman D, Amant F. Screening for uterine tumors. Best Pract Res Clin Obstet Gynaecol. 2012; 26(2): 257-66.

10. Schoenfelder T, Klewer J, Kugler J. Factors Associated with Patient Satisfaction in Surgery: The Role of Patient's Perceptions of Received Care, Visit Characteristics, and Demographic Variables. J Surg Res. 2012; 164(1): 53-59.

11. Schlosser RW. Goal attainment scaling as a clinical measurement technique in communication disorders: a critical review. J Commun Disord. 2004; 37: 217-39.

12. Srikrishna S, Robinson D, Cardozo L. A longitudinal study of patient and surgeon goal achievement 2 years after surgery following pelvic floor dysfunction surgery. BJOG. 2010; 117: 1504-1511.

13. Reis N, Beji NK. Risk factors for endometrial cancer in Turkish women: Results from a hospital-based-case-control study. Eur J Oncol Nurs. 2009; 13: 122-127.

14. Romundstad P, Janszky I, Vatten L, Hakon Bjorngard J, Langhammer A, Manczuk M, et al. Cancer risk factors in Poland: the PONS Study. Ann Agric Environ Med. 2011; 18: 251-254.

15. Linkboy F, Maxwell GL, Felix AS, Lin Y, Lenzer D, Bovbjerg DH, Lokshin A, Hennon M, Jakcic JM, Goodpaster BH, Delany JP. Longitudinal evaluation of cancer- associated biomarkers before and after weight loss in RENEW study participants: Implications for cancer risk reduction. Gynecol Oncol. 2012; 125(1): 114-9.
16. El-Sahwi KS, Schwartz PE, Santin AD. Development of targeted therapy in uterine serous carcinoma, a biologically aggressive variant of endometrial cancer. Expert Rev Anticancer Ther. 2012; 12(1): 41-49.

17. Berstein LM, Boyarkina MP, Teslenko SY. Familial diabetes is associated with reduced risk of cancer in diabetic patients: a possible role for metformin. Med Oncol. 2012; 29(2): 1308-13.

18. Bovbjerg EV, Trowbridge ER, Barber Martirosian TE, Steers WD, Hullfish KL. Patient-centered treatment goals for pelvic floor disorders: association with quality-of-life and patient satisfaction. Am J Obstet Gynecol. 2009; 568: 1-6.

19. Mahajan ST, Elkadry EA, Kenton KS, Shott S, Brubaker L. Patientcentred surgical outcomes: The impact of goal achievement and urge incontinence on patient satisfaction one year after surgery. Am J Obstet Gynecol. 2006; 194: 722-728.

20. Adams SR, Dramitinos P, Shapiro A, Dodge L, Elkadry E. Do patient goals vary with stage of prolapse? Am J Obstet Gynecol. 2011; 205(5)502:1-6.

21. Chan YM, Ngan HYS, Li BYG, Yip AMW, Lee PW, Yip PSF, Wong LC. A Longitudinal Study on Quality of Life after Gynecologic Cancer Treatment. Gynecol Oncol. 2001; 83: 10-19.

22. Hjörleifsdóttir E, Hallberg IR, Gunnarsdőttir ED. Satisfaction with care in oncology outpatient clinics: psychometric characteristics of the Icelandic EORTC IN-PATSAT 32 version. J Clin Nurs. 2010; 19(13-14): 1784-1794.

23. Arrora V, Philips S, Natress K, Pather S, Dalrymple C, Atkinson K, Smirnova S, Cotterell S, Carter J. Patient satisfaction with inpatient care provided by the Sydney Gynecological Oncology Group. Patient Relat Outcome Meas. 2010; 1: 179-184.

24. Arraras JI, Vera R, Martinez M, Hernadez B, Lainez N, Rico M, Vila M, Chicata V, Asin G. The EORTC cancer in-patient satisfaction with care questionnaire: EORTC IN-PATSAT32 Validation study for Spanish patients. Clin Trans Oncol. 2009; 11(4): 237-242.

25. Jayasekara H, Rajapaksa L, Brédard A. Psychometric evaluation of the European Organization for Research and Treatment of Cancer inpatient satisfaction with care questionnaire ('Sinhala' version) for use in a South- Asian setting. Int J Qual Health Care. 2008; 20(3): 221-226.

26. Balderas-Peña LM, Sat-Muñoz D, Contreras-Hernández I, SolanoMurillo P, Hernández-Chávez GA, Mariscal-Ramírez I, Lomelí-García M, Díaz-Cortés MA, Mould-Quevedo JF, Castro-Cervantes JM, GarcésRuiz OM, Morgan-Villela G. Evaluation of patient satisfaction with the quality of health care received within the EORTC IN-PATSAT32 trial by patients with breast and colorectal cancer, and non-Hodgkin lymphoma at different stages. Correlation with socio-demographic characteristics, co-morbidities and other procedural variables at the Mexican Institute of Social Security. Value Health. 2011; 14: 96-99. 